\title{
Investigation of Wheeled Mobility Device Orientation and Movement on Streetcars and Light Rail Vehicles during Normal and Emergency Braking
}

Andrea Mather and K.M. Hunter-Zaworski, Ph.D., P.E.

Oregon State University

\begin{abstract}
Wheeled mobility devices have been accessing public transit vehicles for decades, and most new rail transit systems are accessible. This has increased ridership by people with disabilities. Side-facing orientation on rail transit vehicles often is considered an option to increase capacity for wheeled mobility devices. This paper reports findings of a study of vehicle dynamics and wheeled mobility device orientation on rail transit vehicles. The study used acceleration data and field observations to evaluate wheeled mobility devices in longitudinal and side-facing orientations on streetcar and light rail vehicles. Results from the study include recommendations for longitudinal-oriented areas for wheeled mobility devices as well as additional public outreach on best practices for passengers who use wheeled mobility devices on rail transit vehicles.
\end{abstract}

Keywords: Wheeled mobility device, orientation, rail transit vehicle dynamics

\section{Introduction}

\section{Background}

The braking regimes of streetcars and light rail transit vehicles are specified by the transit industry and transit agency standards (APTA 2013; German Institute for Standardization 2015). Routinely, these regimes are tested as part of the acceptance procedures of new transit vehicles. The research reported in this paper evaluated the movement of occupied wheeled mobility devices in longitudinal and side-facing orientations during normal, emergency, and panic braking regimes on new streetcar and light rail vehicles on rail test tracks. 
The term "longitudinal seating" describes both forward- and rear-facing seating orientation. The research team used the same procedures used for vehicle dynamics tests of small and large transit buses (Hunter-Zaworski 2009; Hunter-Zaworski and Zaworski 2009; Zaworski et al. 2007). Several studies have related acceleration and braking as a measure of passenger ride comfort on rubber-tired vehicles but, to date, none have been reported for rail transit vehicles.

Rail transit vehicle acceleration is controlled by the vehicle's electrical system. The acceleration regime parameters are specified by the operating transit agency during vehicle procurement. Rail transit vehicle acceleration for streetcars and street-running light rail transit (LRT) vehicles are very low and are not of concern in this study; rail transit vehicle braking is the focus of this study.

Hoberock was the first to study transit vehicle braking behavior. Braking behavior, characterized by deceleration rate and jerk, is used as a measure of ride comfort (Hoberock 1976). Jerk is the rate of change of acceleration. There are significant differences in the level of tolerance between side-facing and longitudinally-seated passengers. Recent studies by the research team on rubber-tired vehicles confirmed the observations that 1) most accidents occur under normal operations and 2) manual wheelchairs and scooters are more unstable than power chairs in rapid deceleration conditions. To mitigate some instability, wheelchair brakes always must be applied, and power wheelchairs and scooters must be powered off (Salipur et al. 2011).

This paper concentrates on streetcars and street-running LRT vehicles using the definitions from the National Transit Database (NTD) to define the modes, as shown in Table 1.

TABLE 1.

NTD Definitions of Rail Transit Vehicles

\begin{tabular}{|c|c|}
\hline MODE & Vehicle Type \\
\hline $\begin{array}{l}\text { Light Rail (LR): Typically an electric railway with a } \\
\text { light-volume traffic capacity compared to heavy rail } \\
\text { (HR), characterized by: } \\
\text { - Passenger rail cars operating singly (or in short, } \\
\text { usually two-car trains) on fixed rails-in shared or } \\
\text { exclusive right-of-way (ROW) } \\
\text { - Low or high platform loading } \\
\text { - Vehicle power drawn from an overhead electric } \\
\text { line via a trolley or a pantograph }\end{array}$ & $\begin{array}{l}\text { Rail cars with: } \\
\text { - Motive capability } \\
\text { - Usually driven by electric power } \\
\text { taken from overhead lines } \\
\text { - Configured for passenger traffic } \\
\text { - Usually operating on exclusive ROW }\end{array}$ \\
\hline $\begin{array}{l}\text { Streetcar Rail (SR): Rail transit systems operating } \\
\text { entire routes predominantly on streets in mixed- } \\
\text { traffic; typically operate with single-car trains } \\
\text { powered by overhead catenaries and with frequent } \\
\text { stops. }\end{array}$ & $\begin{array}{l}\text { Rail cars with: } \\
\text { - Motive capability } \\
\text { - Usually driven by electric power } \\
\text { taken from overhead lines } \\
\text { - Configured for passenger traffic } \\
\text { - Often operate in shared-use } \\
\text { corridors (shared ROW) } \\
\text { - Typically operate with one-car trains }\end{array}$ \\
\hline
\end{tabular}

Source: NTD 2015 
Three general classifications of wheeled mobility devices were considered and are defined as follows.

\section{Manual Wheelchairs}

Manual chairs were the most common mobility devices in the past decades. They are light, some are foldable, and they have large rear wheels and small front casters and are used mainly by people with strong arms to propel themselves. They have push bars at the rear for occupants who cannot propel themselves and are pushed by another person, typically used in hospitals, transportation terminals, and institutional places. The "common manual wheelchair," measuring 25 inches wide and 42 inches long when occupied, was for many years used as a base for regulations and standards, with a recommended footprint of $30 \times 48$ inches and a turning radius of 36 inches. Securement systems were developed to secure the wheelchair to vehicles, mainly by tie-downs, to prevent forward and rearward movement (Hunter-Zaworski and Rutenberg 2014).

\section{Power Wheelchairs}

Power wheelchairs are powered by batteries and controlled by joysticks or other types of controllers. They may have special postural control systems or cushioned seats and back, a headrest, and padded armrests. These devices typically measure about 25 inches wide by 38-43 inches long and can weigh up to 300-400 pounds depending on their power pack and accessories. They are usually very nimble, have a small turning radius of about 28 inches, and usually can be accommodated on public transportation vehicles, provided the user is capable of maneuvering in and out of his/her position on-board a vehicle. Powered chairs may have added features to tilt the chair and provide extended leg and upper body supports; these additional features increase the length and weight and can easily exceed the standard footprint of $30 \times 48$ inches. These extra features may make transport on regular public transit vehicles more difficult due to the difficulty of using a front door ramp or lift (Hunter-Zaworski and Rutenberg 2014).

\section{Scooters}

Designed primarily for indoor use, scooters generally have 3 or 4 wheels and typically have a pedestal seat with a tiller or joystick control and small wheels. Many bases of scooters are narrow, with a width of about 20 inches, making them more prone to tipping. In addition, scooters often are procured outside the medical prescription process; many scooter riders do not receive proper training or recommendations for the correct scooter for their size and mobility level (Hunter-Zaworski and Rutenberg 2014).

This paper reports on experiments that were conducted using a standard manual wheelchair and a four-wheel scooter. Prior research conducted by the team has shown that a power-base wheeled mobility device is more stable than either a manual wheelchair or scooter. 


\section{Orientation of Wheeled Mobility Devices}

Prior to the regulations associated with the Americans with Disabilities Act (ADA), sled tests showed that manual wheelchairs did not withstand side accelerations (Stewart and Reni 1981). These results contributed to the ADA regulations that specify that a wheeled mobility device (WhMD) always should be transported oriented in the longitudinal direction on rubber-tired vehicles (ADA Accessibility Specifications for Transportation 1998). Subsequent sled testing of securement systems and WhMDs has confirmed that in high acceleration (high " $\mathrm{g}$ ") environments, the WhMD must be in the longitudinal direction.

In many cities, rail transit systems are built to meet the increases in demand for public transit and population density. Rail transit operators are studying methods to increase vehicle capacity for WhMDs. Side-facing seating orientation for WhMDs is considered an option to increase rail vehicle capacity for WhMD. It also is widely observed that in crowded conditions, many passengers in WhMDs sit sideways in or near the vehicle vestibule because they cannot access areas designated for wheeled mobility devices. This study examined whether side-facing orientation is a viable option for rail transit based on braking studies conducted on light rail test tracks.

\section{Vehicle Dynamics of Rail Transit Vehicles}

The dynamic behavior of rail transit vehicles is significantly different from rubber-tired vehicles. The acceleration and deceleration of rubber-tired vehicles are much more variable because of the operator, tires, pavement and traffic conditions, and vehicle propulsion and transmission systems. In this study, the differences in the coefficient of friction between rubber-tire and steel-tire vehicles influenced the rate of acceleration and deceleration. In rubber-tire operations, large transit buses will experience much higher longitudinal and lateral acceleration forces than rail transit vehicles due to operating conditions and roadway geometrics.

In the United States, most streetcars and street-running LRT systems are electric, and the parameters for acceleration and braking are preset and controlled.

\section{Scope of Study}

This study examined the movement of occupied WhMDs in two different orientations during routine and emergency braking regimes of streetcars and light rail vehicles. The research questions addressed were:

- Do occupied wheeled mobility devices require securement or containment on streetcars or light rail vehicles that operate in traffic?

- Is side-facing orientation an option for occupied wheeled mobility aids on streetcars or light rail vehicles? 
The focus of this study examined the orientation of WhMDs and brake testing regimes on new light rail and streetcar vehicles. The study used both video recordings of movement and an accelerometer-based data acquisition system to record vehicle dynamics. To analyze the effect of the extreme braking regimes on an occupied WhMD, a $50^{\text {th }}$ percentile male anthropometric test dummy was used for all tests and to simulate a passenger with very low or no upper body strength. Two types of WhMDs were used in this study - a standard manual wheelchair and a four-wheel scooter. Both WhMDs were considered to be in used condition; however, the manual wheelchair had functional brakes, and the scooter could be powered off.

During testing, the WhMDs were oriented in either longitudinal or side-facing orientations. Most transit systems operate trains bi-directionally, and during testing they operated bi-directionally. The WhMD faced either forward or rearward when they were positioned longitudinally. Similarly, when the WhMDs were positioned in the sidefacing orientation, they were exposed to braking forces on tangent, concave, and convex curved track.

\section{Description of Testing}

The streetcar and light rail vehicle were electrically-powered, and the vehicle electronic control system limited the vehicle acceleration that occurs when a train leaves a station. Full accelerations were evaluated, but the resulting movement by the test dummy and WhMDs in all orientations were insignificant.

The evaluation of braking regimes for regular, full, and emergency braking was included in this study. To evaluate the impact of not applying brakes on the manual wheelchair, a member of the research team occupied it and did not set the brakes; it was necessary for the researcher to manually restrain the wheelchair chair to prevent excessive motion.

Testing occurred at two locations. The streetcar was evaluated on the United Streetcar test track in Clackamas, Oregon, and the light rail vehicle was evaluated on the TriMet test track in Gresham, Oregon.

\section{Braking Regimes}

The three braking regimes included in this study for both streetcar and light rail vehicles were 1) normal braking from 25 miles per hour ( $\mathrm{mph}$ ) to full stop at a station, 2) emergency stops, and 3) panic stops (only on tangent sections). For the TriMet light rail tests, the braking regime specification depended on whether the bogies or trucks have power. There were three bogies per vehicle-two powered with electric motors and one without power, located in the articulated or middle section of the vehicle. The powered bogies had both electrodynamic braking systems with a back-up friction brake system. The unpowered bogie had only a friction brake system. The control of the braking was independent on speed except for in some modes of friction-only braking. The braking regime depended upon requested and actual achieved braking rates and were dependent on passenger loads and rail adhesion levels. The powered bogies provided 
most of the braking force, primarily by electrodynamic braking. The unpowered bogie assisted in braking only if there was a high passenger load or the vehicle was not reaching the commanded brake rate. Normal service braking or deceleration rates are:

- Normal service braking—ranges from $0.426 \mathrm{ft} / \mathrm{s}^{2}$ to $4.4 \mathrm{ft} / \mathrm{s}^{2}\left(0.13 \mathrm{~m} / \mathrm{s}^{2}\right.$ to $\left.1.34 \mathrm{~m} / \mathrm{s}^{2}\right)$

- Emergency and safety braking rates $-7.67 \mathrm{ft} / \mathrm{s}^{2}\left(2.34 \mathrm{~m} / \mathrm{s}^{2}\right)$ minimum

The characteristics of the streetcar and light rail test tracks limited the scope of testing. Both test tracks are level track. The TriMet test track has a short tangent section of track that limits the maximum speed to $25 \mathrm{mph}$. The test track allowed for low-speed braking on the highly-curved sections. Due to the risk of damage to both the rail and vehicle wheels, panic brake regime tests were completed only once per site.

During the light rail vehicle tests, the manual wheelchair and four-wheel scooter were occupied by a male test dummy. The wheelchair had brakes applied and was occupied by the test dummy, and the scooter had its power turned off and was occupied by the test dummy.

\section{Streetcar (United Streetcar Test Track)}

United Streetcar manufactures the streetcars used by the City of Portland and other cities. The manufacturing facility has a test track with both tangent and highly-curved sections of track. During testing, the tracks were wet due to rain, but no excessive skidding was observed. Trains operated bi-directionally on the track. In the tests, the male test dummy occupied the manual wheelchair. The wheelchair brakes were applied during most of the tests, and the wheelchair was oriented in the longitudinal position, with the arm of the dummy over the fold-up seat.

\section{Streetcar Testing and Observations}

The testing at United Streetcar included the male test dummy occupying a manual wheelchair. The standard regular and emergency braking regimes were tested. Testing occurred with the wheelchair brakes engaged and oriented longitudinally. When the wheelchair was oriented in the side-facing direction, it encroached into the travel path of passengers. During the brake tests, when the dummy's arm was on the back of the side-facing folded-up seats, there was no significant movement. There was a little more movement, but none of concern, when the dummy's arm was resting in the lap of the dummy. This showed that a person holding onto a seat back prevents movement even in an emergency braking regime, similar to a passenger holding onto a stanchion.

Observations showed that a side-facing orientation of a WhMD severely affects interior circulation in the aisle and other spaces. A side-facing orientation of an WhMD during braking was not evaluated on the streetcar due to the restricted interior circulation. 


\section{Light Rail (TriMet Test Track)}

Conducted in May 2015, primary testing took place at TriMet's light rail maintenance facility in Gresham, Oregon. The test track was dry. The test track is primarily a flat tangent section, although low-speed brake tests were conducted on a sharply-curved section of track. There were negligible elevation changes in the track. The light rail vehicles were coupled as a married pair and operated bi-directionally. The bi-directional operation permitted both forward and rear-facing orientation for the wheeled mobility devices, and the side-facing orientation permitted the use of a side barrier in one direction only. Regular and emergency brake tests were conducted on the curve section. No panic stops were conducted on curve sections.

\section{Light Rail Testing and Observations}

Data collection involved the use of accelerometer data, video recording, and visual observations. The three-dimensional accelerometers used were Gulf Coast Data Concepts Data USB X2-2 data loggers that included high-sensitivity, low-noise, threeaxis $+/-2 \mathrm{~g}$ accelerometer sensors. Each was calibrated and collected data at $100 \mathrm{hz}$.

The accelerometers were placed on the floor of the vehicle and were orientated longitudinally or in line with the direction of travel. To ensure data collection, two accelerometers collected data, which was transferred to Microsoft Excel for further analysis. During testing, a hand-held video camera recorded the WhMD movement. A researcher recorded all videos from the same point in the vehicle. Visual observations by the remaining researchers and agency staff also were recorded for other points in the vehicle. The test dummy was side-facing for all the tests except the first panic stop when the test dummy was in the longitudinal orientation.

\section{Testing Results}

The results showed that during regular braking, the deceleration observed was in the $0.15 \mathrm{~g}$ range. During panic stops, the maximum observed deceleration was $0.41 \mathrm{~g}$. These were within the specified range for the vehicles.

The following tables describe the tests and the observed motion of each test and maximum deceleration. The description of the tests includes the restraint of the test dummy and the track geometry. The driving regime section includes the different movements testing. The observed movement section includes the information on the different types of movement of the WhMD encountered during the test. It is important to note that the accelerations recorded and presented were for vehicle acceleration and not for the WhMD or test dummy.

One operator drove the train for testing on the tangent track. The manual chair occupied by the test dummy was tested first; the test dummy then was moved to the scooter, and the tests were repeated. A different vehicle operator drove the train on the curved track tests, and only the scooter was tested with the test dummy. 
Tables 2 and 3 show the test plan and observed accelerations of the occupied manual wheelchair. The tests used both tangent and curved track at the TriMet testing facilities. Testing included a control test with regular acceleration and deceleration before each test group. Illustrated are the performance of the control tests prior to the experimental braking tests. For the curved track test, only rapid decelerations were tested. On the tangent track, tests of rapid acceleration and panic stops were conducted. The variables that changed during this testing were the track geometry, upper body restraint, and test deceleration.

TABLE 2.

Straight Track Test Description, Results, and Observations for Manual

Wheelchair

\begin{tabular}{|c|c|c|c|c|c|c|}
\hline $\begin{array}{c}\text { Test } \\
\#\end{array}$ & \multicolumn{2}{|c|}{ Description } & \multicolumn{2}{|c|}{ Driving Regime } & $\begin{array}{c}\text { Max } \\
\text { Acceleration }\end{array}$ & Observed \\
\hline \multirow{3}{*}{1} & $\begin{array}{l}\text { Upper body } \\
\text { used for } \\
\text { restraint }\end{array}$ & YES & $\begin{array}{c}\text { Control } \\
\text { movement }\end{array}$ & $\begin{array}{c}\text { Normal } \\
\text { acceleration/ } \\
\text { deceleration }\end{array}$ & $0.12 \mathrm{~g}$ & None \\
\hline & \multirow{2}{*}{ Track type } & \multirow{2}{*}{$\begin{array}{l}\text { Straight } \\
\text { track }\end{array}$} & $\begin{array}{c}\text { Test } \\
\text { movement }\end{array}$ & $\begin{array}{c}\text { Rapid } \\
\text { acceleration }\end{array}$ & $0.15 \mathrm{~g}$ & None \\
\hline & & & $\begin{array}{c}\text { Test } \\
\text { movement }\end{array}$ & Panic stop & $0.39 \mathrm{~g}$ & None \\
\hline \multirow{3}{*}{2} & $\begin{array}{l}\text { Upper body } \\
\text { used for } \\
\text { restraint }\end{array}$ & $\mathrm{NO}$ & $\begin{array}{c}\text { Control } \\
\text { movement }\end{array}$ & $\begin{array}{c}\text { Normal } \\
\text { acceleration/ } \\
\text { deceleration }\end{array}$ & $0.15 \mathrm{~g}$ & None \\
\hline & \multirow[b]{2}{*}{ Track type } & \multirow[b]{2}{*}{$\begin{array}{c}\text { Straight } \\
\text { track }\end{array}$} & $\begin{array}{c}\text { Test } \\
\text { movement }\end{array}$ & $\begin{array}{c}\text { Rapid } \\
\text { acceleration }\end{array}$ & $0.147 \mathrm{~g}$ & None \\
\hline & & & $\begin{array}{c}\text { Test } \\
\text { movement }\end{array}$ & Panic stop & $0.398 \mathrm{~g}$ & $\begin{array}{c}\text { Slight movement; } \\
\text { casters moved, } \\
\text { device moved } \\
\text { within designated } \\
\text { area }\end{array}$ \\
\hline
\end{tabular}

TABLE 3.

Curved Track Test Description, Results, and Observations for Manual Wheelchair

\begin{tabular}{|c|c|c|c|c|c|c|}
\hline $\begin{array}{c}\text { Test } \\
\#\end{array}$ & \multicolumn{2}{|c|}{ Description } & \multicolumn{2}{c|}{ Driving Regime } & $\begin{array}{c}\text { Max Acceleration } \\
\text { Observed }\end{array}$ & $\begin{array}{c}\text { Observed } \\
\text { Movement }\end{array}$ \\
\hline \multirow{3}{*}{3} & $\begin{array}{c}\text { Upper body } \\
\text { used for } \\
\text { restraint }\end{array}$ & YES & $\begin{array}{c}\text { Control } \\
\text { movement }\end{array}$ & $\begin{array}{c}\text { Normal } \\
\text { acceleration/ } \\
\text { deceleration }\end{array}$ & $0.09 \mathrm{~g}$ & None \\
\cline { 2 - 7 } & Track type & $\begin{array}{c}\text { Curve } \\
\text { track }\end{array}$ & $\begin{array}{c}\text { Test } \\
\text { movement }\end{array}$ & $\begin{array}{c}\text { Rapid } \\
\text { acceleration }\end{array}$ & $0.12 \mathrm{~g}$ & None \\
\hline \multirow{2}{*}{4} & $\begin{array}{c}\text { Upper body } \\
\text { used for } \\
\text { restraint }\end{array}$ & NO & $\begin{array}{c}\text { Control } \\
\text { movement }\end{array}$ & $\begin{array}{c}\text { Normal } \\
\text { acceleration/ } \\
\text { deceleration }\end{array}$ & $0.08 \mathrm{~g}$ & None \\
\cline { 2 - 7 } & Track type & $\begin{array}{c}\text { Curve } \\
\text { track }\end{array}$ & $\begin{array}{c}\text { Test } \\
\text { movement }\end{array}$ & $\begin{array}{c}\text { Rapid } \\
\text { acceleration }\end{array}$ & $0.15 \mathrm{~g}$ & None \\
\hline
\end{tabular}

Scooter testing followed a testing sequence similar to manual chair testing. Control movements and test movements were tested. The scooter testing included testing on tangent and curved track. The scooter was tested in a side-facing orientation in the same securement location as the manual chair that was used for the tangent section. Tables 4 and 5 shows the test plan and observations for the scooter. 
TABLE 4.

Straight Track Test

Description, Results and

Observations for Scooter

\begin{tabular}{|c|c|c|c|c|c|c|}
\hline $\begin{array}{c}\text { Test } \\
\#\end{array}$ & \multicolumn{2}{|c|}{ Description } & \multicolumn{2}{|c|}{ Driving Regime } & $\begin{array}{c}\text { Max } \\
\text { Acceleration } \\
\text { Observed }\end{array}$ & $\begin{array}{l}\text { Observed } \\
\text { Movement }\end{array}$ \\
\hline \multirow{3}{*}{1} & $\begin{array}{l}\text { Upper body } \\
\text { used for } \\
\text { restraint }\end{array}$ & YES & $\begin{array}{c}\text { Control } \\
\text { movement }\end{array}$ & $\begin{array}{l}\text { Normal } \\
\text { acceleration/ } \\
\text { deceleration }\end{array}$ & $0.14 \mathrm{~g}$ & None \\
\hline & \multirow{2}{*}{ Track Type } & \multirow{2}{*}{$\begin{array}{l}\text { Straight } \\
\text { track }\end{array}$} & Test movement & Rapid acceleration & $0.15 \mathrm{~g}$ & None \\
\hline & & & Test movement & Panic stop & $0.41 \mathrm{~g}$ & None \\
\hline \multirow{3}{*}{2} & $\begin{array}{l}\text { Upper body } \\
\text { used for } \\
\text { restraint }\end{array}$ & NO & $\begin{array}{c}\text { Control } \\
\text { movement }\end{array}$ & $\begin{array}{c}\text { Normal } \\
\text { acceleration/ } \\
\text { deceleration }\end{array}$ & $0.13 \mathrm{~g}$ & None \\
\hline & \multirow[b]{2}{*}{ Track Type } & \multirow[b]{2}{*}{$\begin{array}{l}\text { Straight } \\
\text { track }\end{array}$} & Test movement & Rapid acceleration & $0.15 \mathrm{~g}$ & None \\
\hline & & & Test movement & Panic stop & $0.27 \mathrm{~g}$ & $\begin{array}{l}\text { Slight } \\
\text { movement of } \\
\text { upper body }\end{array}$ \\
\hline
\end{tabular}

TABLE 5.

Curved Track Test Description, Results, and Observations for Scooter

\begin{tabular}{|c|c|c|c|c|c|c|}
\hline \multirow{3}{*}{$\begin{array}{c}\text { Test } \\
\# \\
\\
3\end{array}$} & \multicolumn{2}{|c|}{ Description } & \multicolumn{2}{|c|}{ Driving Regime } & \multirow{2}{*}{$\begin{array}{c}\text { Max } \\
\begin{array}{c}\text { Acceleration } \\
\text { Observed }\end{array} \\
0.06 \mathrm{~g}\end{array}$} & \multirow{2}{*}{$\begin{array}{c}\text { Observed } \\
\text { Movement } \\
\text { None }\end{array}$} \\
\hline & $\begin{array}{c}\text { Upper body } \\
\text { used for restraint }\end{array}$ & YES & $\begin{array}{c}\text { Control } \\
\text { movement }\end{array}$ & $\begin{array}{c}\text { Normal acceleration/ } \\
\text { deceleration }\end{array}$ & & \\
\hline & Track Type & $\begin{array}{l}\text { Curve } \\
\text { track }\end{array}$ & $\begin{array}{c}\text { Test } \\
\text { movement }\end{array}$ & Rapid acceleration & $0.11 \mathrm{~g}$ & None \\
\hline \multirow{2}{*}{4} & $\begin{array}{c}\text { Upper body } \\
\text { used for restraint }\end{array}$ & NO & $\begin{array}{c}\text { Control } \\
\text { movement }\end{array}$ & $\begin{array}{c}\text { Normal acceleration/ } \\
\text { deceleration }\end{array}$ & $0.02 \mathrm{~g}$ & None \\
\hline & Track Type & $\begin{array}{l}\text { Curve } \\
\text { track }\end{array}$ & $\begin{array}{c}\text { Test } \\
\text { movement }\end{array}$ & Rapid acceleration & $0.08 \mathrm{~g}$ & None \\
\hline
\end{tabular}

The only tests that showed movement of the WhMD were the panic stops. If the upper body of the test dummy was propped on the seat back, there was no observed movement. This confirms observations that when passengers hold onto stanchions or the back of a seat, their movement is limited.

The third part of the testing included a researcher sitting in the manual chair without any brakes or upper body restraint while the train traveled on the tangent and curved track sections; this was included to illustrate the effectiveness of the WhMD brakes. The performance of this test illustrates the effectives of the WhMD on-board braking system. Test performance did not occur during any rapid acceleration or deceleration tests because of safety concerns.

The largest change in acceleration was in the longitudinal direction for all tests. The largest accelerations occurred during panic stops or rapid decelerations. Figures 1 and 2 show plots of the test segments when the rail vehicle went into a panic stop. Note that the vertical scale in the two diagrams is not the same. The graphs show the constant velocity phase (zero acceleration) that preceded the application of the brakes, followed by rapid decelerations, followed by the application of the track brake that produces a significant "jerk" reaction. The last segment shows the "damping" effect of the vehicle 
Panic brake longitudinal acceleration (light rail vehicle)

suspension system. Jerk is the rate of change of acceleration and, often, the jerk causes standing passengers to lose their balance and seated passengers to reach for a stanchion or armrest. Observable "jerk" occurred in all braking tests. The panic braking tests were the only tests in which all researchers reached for stanchions and arm rests for stability. In Figure 2, the "jerk" on the street car is larger than the "jerk" on the light rail vehicle and this is attributable to the difference in mass and suspension systems of the two vehicles.

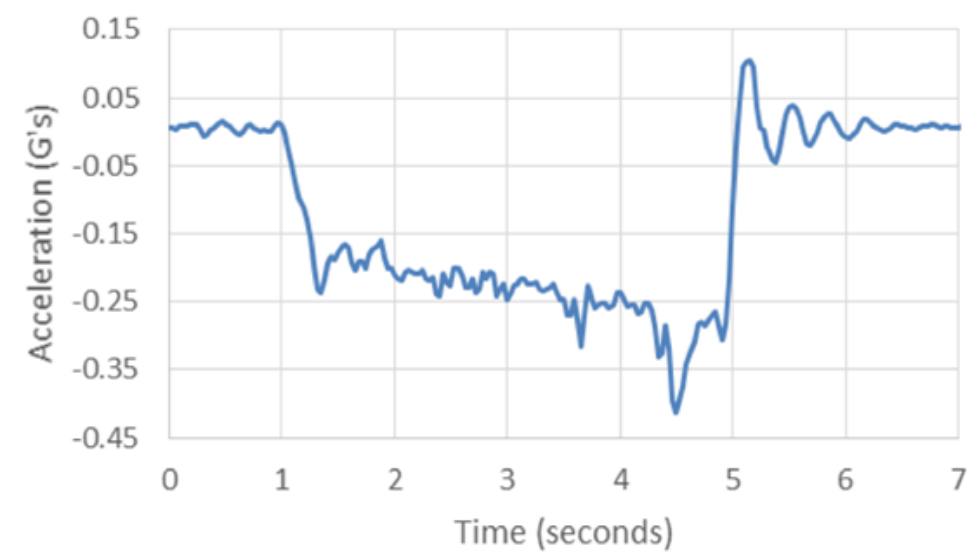

FIGURE 2.

Longitudinal acceleration panic stop (streetcar)

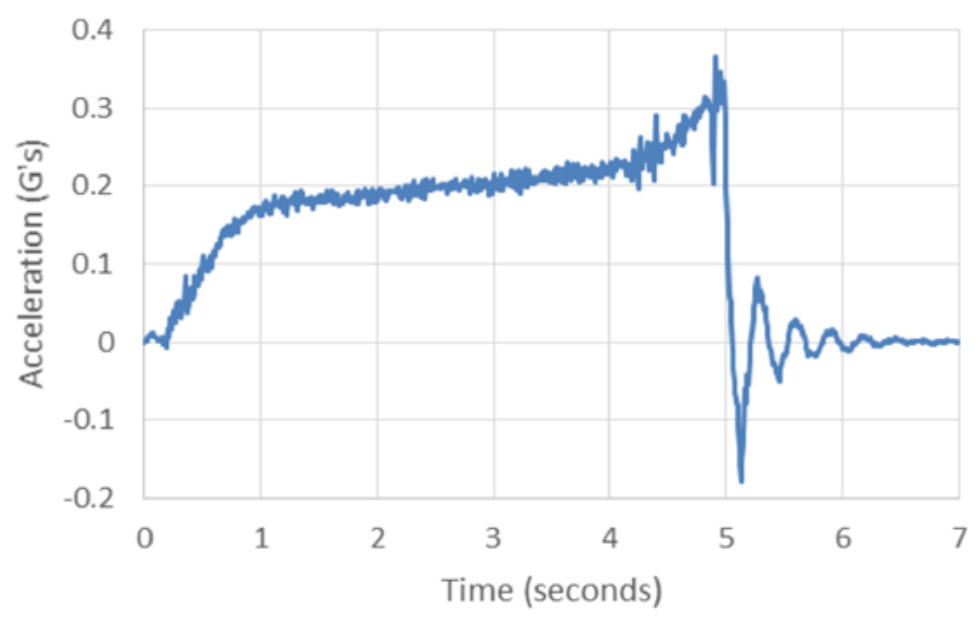

The data collected by the accelerometers was independent of the securement type, WhMD, and direction of securement. The placement of the accelerometers was on the vehicle and not on the WhMD. The sign of the acceleration also was dependent on vehicle direction. The accelerometer directions were not changed when the train reversed direction. The change in magnitude of acceleration response is of interest when reporting acceleration.

All testing was within the parameters for TriMet, with the overall maximum acceleration of $0.41 \mathrm{~g}$ in the longitudinal direction for light rail. For streetcar data, the maximum acceleration was recorded at $0.36 \mathrm{~g}$. Table 6 summarizes these results. Note the large difference in maximum acceleration for different movements. The panic stop resulted in much larger accelerations than rapid acceleration. 
TABLE 6.

Summary of Maximum Accelerations

\begin{tabular}{|c|l|c|}
\hline Vehicle & \multicolumn{1}{|c|}{ Movement } & $\begin{array}{c}\text { Max } \\
\text { Acceleration }\end{array}$ \\
\hline Light rail & Rapid acceleration & $0.15 \mathrm{~g}$ \\
\hline Light rail & Panic stop & $0.41 \mathrm{~g}$ \\
\hline Streetcar & Panic stop & $0.36 \mathrm{~g}$ \\
\hline
\end{tabular}

\section{Discussion of Results}

\section{Side-facing Orientation}

During the light rail testing at TriMet, the side-facing orientation of the scooter and the manual wheelchair did not show significant movement during the regular or emergency braking regimes when the brakes were applied on the manual wheelchair or when the scooter was powered off. Active control by the occupant was needed during occupied side-facing testing when the brakes were not set. It was observed that the toes and footplates of the manual wheelchair and the front of the scooter both encroached into the aisle of the rail vehicle, impacting the interior circulation of passengers standing or moving through the aisle. This resulted in a reduced flow of passengers passing the securement areas. Figure 3 shows the side-facing test dummy. It is important to note that the right arm of the test dummy in the photo is resting on the top of the flipped-up seat, and the front casters are rotated, which can increase instability. The wheelchair brakes were engaged in this photo.

FIGURE 3.

Side-facing occupied manual wheelchair on light rail vehicle

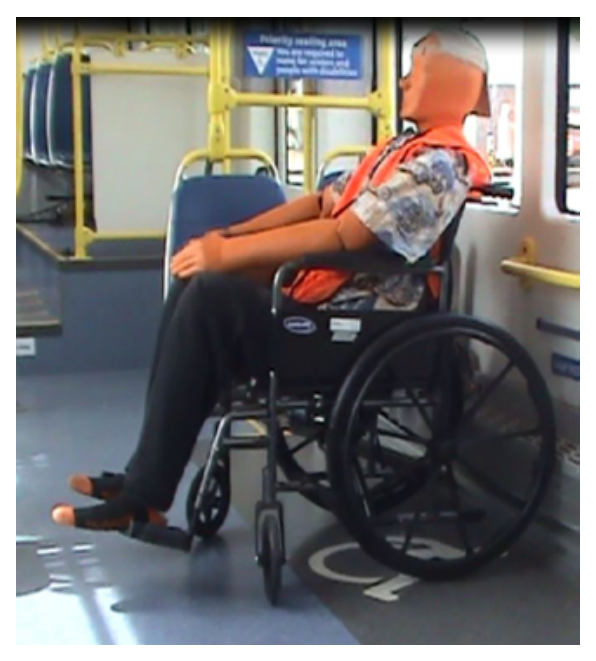

\section{Containment Type}

In both streetcar and light rail vehicle testing, it was observed that when the dummy's arm was put on the flipped seat back for forward and rearward orientation or on a modesty panel for side-facing, there was almost no motion of the WhMD during all braking regimes. This is analogous to passengers holding onto stanchions or bracing 
against a seat. Figure 4 shows a manual wheelchair in the longitudinal orientation with the dummy's arm resting on a horizontal bar. Slight movement of the WhMD occurred when the dummy's arm was not restrained. The movement did not result in movement outside the securement area or any tipping.

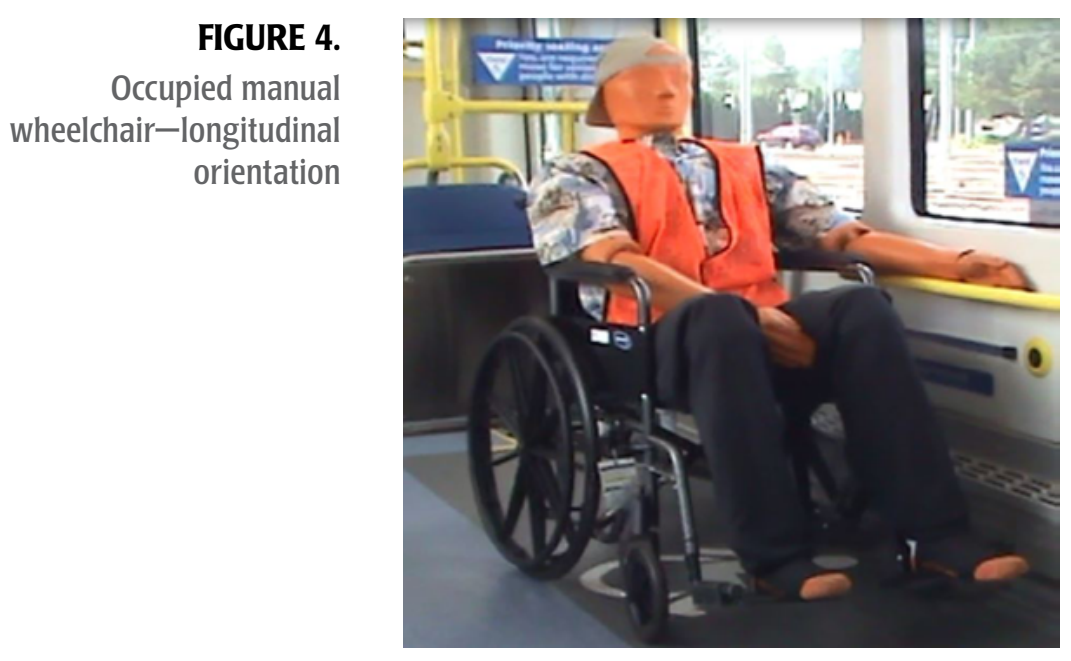

The brakes on the WhMD were applied during all brake tests that when the dummy was used. To evaluate the effectives of the brakes on the wheelchair, a researcher occupied the manual wheelchair without applying the brakes. During normal braking conditions on tangent and curved sections of the track, the wheelchair moved around the vehicle and the researcher had to control the motion of the wheelchair actively. The wheelchair moved outside the designated area, but it did not tip, and all four wheels stayed in contact with the floor of the vehicle during the test.

\section{Conclusions and Recommendations}

The results showed that most people would not experience large movements during emergency braking in any of the orientations of the WhMDs when the WhMDs either are powered off or have functioning brakes. The tests on the light rail vehicles showed that side-facing and longitudinal orientations are options. Although both orientations are viable, the longitudinal orientation of the WhMD avoided incursions into the aisle space and reduced the impact on other passenger moving through the vehicle. This is especially important for crowded vehicles. The movement in either orientation was very small, even in the lightweight mobility aids.

During the side-facing testing on the light rail vehicle, it was difficult for standing passengers to move around the $\mathrm{WhMD}$ and access other parts of the vehicle. Train operators expressed concern about the need for a clear aisle during regular and emergency operations.

All the testing procedures showed the importance of WhMDs applying brakes or powering off and the impact on movement of the WhMD during regular and 
emergency braking regimes. Active control of the wheelchair was necessary to prevent it from moving around the vehicle when the brakes were not used on the manual wheelchair.

The tests also showed that all passengers should hold onto a stanchion or seatback to minimize movement during braking. Recommendations include developing and placing placards onboard the vehicle to indicate to $\mathrm{WhMD}$ passengers the location of safe areas to hold on for those who are able. In addition, placards should remind WhMD passengers to use their brakes or power off.

In summary, longitudinal orientation is recommended for all transit vehicles. Side-facing orientation does not pose a significant safety risk on rail transit vehicles, as it does on bus transit during braking. Side-facing orientation may be convenient during short trip segments when it is difficult for WhMD passengers to access the space assigned to passengers with disabilities. It should be noted that large WhMDs might influence internal circulation for other passengers.

\section{Recommendations for Future Testing}

The tests performed did not measure the impact of vertical curvature. The research team recommends the need for further testing on tracks with vertical curves. Whereas track vertical curvatures are much lower than on roadways, there are elevation changes. A positive or negative vertical grade change could impact the stability of the wheeled mobility devices, which is likely to be especially important during side-facing orientation.

\section{References}

Americans with Disabilities Act, Accessibility Specifications for Transportation Vehicles. 1998. 49 CFR Part 38, September.

American Public Transportation Association (APTA). 2013. "Modern Streetcar Vehicle Guideline." APTA Standards Development Program. Washington, DC.

German Institute for Standardization. 2005. European Railway Applications-BrakingMass Transit Brake Systems_-Part 1: Performance Requirements. DIN-EN 134521:2005

Hoberock, L. L. 1976. "A Survey of Longitudinal Acceleration Comfort Studies in Ground Transportation Vehicles." Research Report 40, Department of Research, Office on University Research, USDOT, Washington, DC.

Hunter-Zaworski, K. M., and U. Rutenberg. 2014. "Use of Mobility Devices on Paratransit Vehicles and Buses." TCRP Report 171, Transportation Research Board, Washington DC.

Hunter-Zaworski, K. M., and J. R. Zaworski. 2009. "Dynamics of Small Transit Vehicles." Final Report, Public Transit Division, Oregon Department of Transportation, June. 
Hunter-Zaworski, K. M., and J. R. Zaworski. 2009. "Independent Wheelchair Securement." IDEA Project T-57 Final Report, National Academies, Washington DC, May.

Federal Transit Administration, Office of Budget and Policy. 2015. National Transit Data Base. http://www.ntdprogram.gov/ntdprogram/Glossaries/pdf/Glossary2014.pdf, accessed June 25, 2015.

Salipur, Z., K. Frost, and G. Bertocci. 2011. "Investigation of Wheelchair Instability during Transport in Large Accessible Transit Vehicles." Journal of Rehabil Res Dev, 49(6): 935-48.

Stewart, C. F., and H. G. Reni. 1981. "Wheelchair Securement on Bus and Paratransit Vehicles." California Department of Transportation, UMTA, NTIS, Report UMTA-CA-06-0098-81-1.

Zaworski. J. R., K. M. Hunter-Zaworski, and M. Baldwin. 2007. "Bus Dynamics for Mobility Aid Securement Design.” Assistive Technology, 19 (Winter): 200-209.

\section{About the Authors}

ANDREA MATHER, EIT (andrea.j.mather@gmail.com) graduated with an M.S. in Civil Engineering (2016) and a B.S Civil Engineering in (2014) bot from Oregon State University.

Katharine Hunter-ZaworsKI, Ph.D., P.E. (hunterz@engr.orst.edu) is an Associate Professor of Civil Engineering at Oregon State University and an internationallyrespected expert in accessible public transportation. 